\title{
Postural hypotension and abnormalities of salt and water metabolism in myelopathy patients
}

\author{
James H Frisbie and David JR Steele
}

Spinal Cord Injury and Medical Services of the Department of Veterans Affairs Medical Center, Brockton/West Roxbury, MA and Harvard Medical School, Boston, Massachusetts, USA

To describe the clinical manifestations of postural hypotension $(\mathrm{PH})$ in myelopathy patients a standardized interview and chart review were carried out. Of 232 myelopathy patients with more than 2 years of paralysis seen during a 2 year period, 30 had been treated for PH. All PH patients were paralysed at levels higher than thoracic 7. The highest risk patients were tetraplegic, motor complete, 24 of $73(33 \%)$. The common symptoms of $\mathrm{PH}$ were those of reduced consciousness $(100 \%)$, strength $(75 \%)$, vision $(56 \%)$ and breath $(53 \%)$. Precipitating factors were hot weather $(77 \%)$ bowel care $(33 \%)$ and meals $(30 \%)$. Symptoms worsened with the duration of paralysis in 12 patients. Chronic hyponatremia was found in $54 \%$ of the $\mathrm{PH}$ patients and $16 \%$ of those without, $P<0.001$. Of five $\mathrm{PH}$-hyponatremic patients with urine sodium and osmolality determinations, five continued to retain water $(>150 \mathrm{mOsm} / \mathrm{kg}$ ) while four failed to conserve salt $(>19 \mathrm{mmol} \mathrm{Na} / \mathrm{L})$. PH is common among myelopathy patients with higher levels of paralysis, symptoms are variable, and abnormal salt and water metabolism often coexist.

Keywords: postural hypotension; orthostasis; hyponatremia; antidiuretic hormone; spinal cord injury; myelopathy

\section{Introduction}

In patients with myelopathy postural hypotension $(\mathrm{PH})$ is a phenomenon associated with a mid thoracic or higher level of paralysis. 1,2 Evident with the first orthostasis after the onset of paralysis, it persists in some patients. ${ }^{3}$ But there are no data as to the prevalence of $\mathrm{PH}$ after the acute phase of paralysis, no systematic descriptions of the symptoms generated by $\mathrm{PH}$ and no indicators of its long term prognosis.

A variety of other conditions associated with autonomic failure such as multiple system atrophy (Shy Drager syndrome), Parkinson's disease, diabetes mellitus, and amyloidosis are complicated by $\mathrm{PH}^{4,5}$ The symptoms are predominately fainting, weakness, and dimming of vision, explainable by reduction in cerebral blood flow. ${ }^{6}$

Physiological studies in tetraplegic patients have demonstrated subnormal catecholamine and supernormal renin and antidiuretic hormone (ADH) responses to $\mathrm{PH}$ induced by tilt table orthostasis., Similar endocrine responses would be expected when $\mathrm{PH}$ accompanies ordinary sitting in a wheelchair. In fact, hyponatremia, a manifestation of ADH activity, is relatively common among acute and chronic myelopathy patients. ${ }^{9,10} \mathrm{ADH}$ activity being induced by postural hypotension, it can be asked whether the hyponatremia of myelopathy patients is particularly prevalent among those with $\mathrm{PH}$.

The clinical effects of known pathophysiology for $\mathrm{PH}$ being generally unexplored in myelopathy patients, a survey for this disability has been conducted to (A) estimate the prevalence of $\mathrm{PH},(\mathrm{B})$ describe the clinical picture and (C) search for abnormalities of salt and water metabolism.

\section{Methods}

\section{Subjects}

All patients admitted to the spinal cord injury service of the Brockton/West Roxbury Veterans Administration Medical Center in 1994 and 1995 whose duration of paralysis was 2 years or more were reviewed. These subjects were described by age, duration of paralysis, level and grade of paralysis.

A subgroup of patients for whom prescriptions for ephedrine had been written were designated as posturally hypotensive, since it is the drug used routinely for $\mathrm{PH}$ and not used for any other purpose in this hospital.

\section{Interview and chart review}

The subgroup of patients for whom ephedrine had been prescribed were interviewed with a standardized 
questionaire to determine symptoms, their course, precipitating factors, treatments, and treatment outcomes. Incidental comments from the subjects were also recorded.

Laboratory records for all patients were reviewed for serum sodium levels. Chronic hyponatremia was designated if at least five serum sodium levels had been recorded and more than half of these levels were less than $135 \mathrm{mEq} / \mathrm{L}$, the lower limit of normal for the hospital laboratory. In selected patients the serum and urine sodium concentrations were determined, simultaneously, to assess sodium conservation by the kidneys. All sodium levels were determined by electrode measurements of serum dialysate (Synchron CX4/CX7 Delta System, Beckman).

A search for known causes of hyponatremia - heart failure, cirrhosis with ascites, nephrotic syndrome, hyperlipidemia, chronic use of diuretics, adrenal insufficiency, hypothyroidism, lung cancer, brain damage, a variety of medications (antineoplastic, carbamazepine, amitriptyline, thioridazine, clofibrate) - was carried out in the patients using ephedrine.

\section{Statistics}

Age and duration of paralysis were expressed as mean and standard deviation. Ephedrine and non-ephedrine groups were compared by a student $t$ test for age and duration of paralysis, by the chi square test for prevalence by level and grade of paralysis and by number of subjects with hyponatremia.

\section{Results}

Subjects

Two hundred and thirty-one patients had been admitted during the 2 year survey period. Thirty of these patients had been treated with ephedrine and were therefore identified as $\mathrm{PH}$. The ephedrine group age was $57 \pm 15$ years and the duration of paralysis $26 \pm 15$ years. The non-ephedrine group was aged $57 \pm 15.2$ and the duration of paralysis $22 \pm 13.5$ years. No significant difference existed between these groups for age or duration of paralysis.

The causes of paralysis were similar in the ephedrine and non-ephedrine groups. See Table 1.

\section{Onset of postural hypotension}

The onset of the symptoms of hypotension could be divided into early and late groups. The early onset group, 20 patients, recalled symptoms within the first year of paralysis. The late onset group, 10 patients, recalled symptoms only many years after paralysis.

The lowest recorded blood pressure for the $\mathrm{PH}$ patients ranged from non-palpable to 100 systolic with a median of $70 \mathrm{mmHg}$. There was no difference in the lowest blood pressures recorded for the early and late onset $\mathrm{PH}$.
Table 1 Causes of paralysis in the ephedrine and nonephedrine groups

\begin{tabular}{lcc}
\hline Causes & $\begin{array}{c}\text { Ephedrine } \\
\text { patients }\end{array}$ & $\begin{array}{c}\text { Non-Ephedrine } \\
\text { patients }\end{array}$ \\
\hline MVA & $13(43)$ & $85(42)$ \\
Fall & $7(23)$ & $52(26)$ \\
GSW & $3(10)$ & $21(11)$ \\
Diving & $5(17)$ & $14(7)$ \\
Falling object & $2(7)$ & $12(6)$ \\
Medical & & $12(6)$ \\
Surgical & & $5(2)$ \\
Totals & 30 & 201 \\
\hline
\end{tabular}

Percentages are in parentheses. MVA $=$ motor vehicle accident and includes pedestrian accidents. GSW $=$ gunshot wound and includes explosions. Medical causes were degenerative disease of the spine, arteriovenous malformation, epidural abscess, poliomyelitits, transverse myelitis, tumour, and arachnoiditis. Surgical causes were related to aortic aneurysms, cervical osteoarthritis and lipoma

\section{Prevalence}

The occurrence of $\mathrm{PH}$ was confined to patients with a level of paralysis higher than T7, Table 2, and was greater for motor complete than for motor incomplete grades of paralysis, Table 3 . The risk for $\mathrm{PH}$ among patients who were both tetraplegic and motor complete at that level was greater than that of the other risk groups combined, Table 4.

\section{Symptoms}

Fainting was reported by all patients receiving ephedrine, other symptoms by fewer, suggesting that fainting was either the most common or the most accepted indication for the use of ephedrine in the population surveyed. The symptoms of the $\mathrm{PH}$ are listed in Table 5.

Several factors induced symptoms of hypotension. Although such factors were recognized infrequently in some patients, all that were recalled have been summarized in Table 6 .

From the time of onset the frequency of symptoms was found to diminish in only three patients, to remain unchanged in 15 , and to worsen in 12 . No patient reported recovery from symptoms.

Table 2 Risk of postural hypotension by the level of paralysis in myelopathy patients

\begin{tabular}{lccc}
\hline $\begin{array}{l}\text { Level of } \\
\text { Paralysis }\end{array}$ & $\begin{array}{c}\text { Ephedrine } \\
\text { patients }\end{array}$ & $\begin{array}{c}\text { Non-Ephedrine } \\
\text { patients }\end{array}$ & Total \\
\hline Cervical & $27(22)$ & 94 & 121 \\
Thoracic 1-6 & $3(8)$ & 33 & 36 \\
Thoracic 7-12 & 0 & 53 & 53 \\
Lumbar & 0 & 21 & 21
\end{tabular}

Percentages are in parentheses. For levels above T7 versus those below T6 ephedrine use was statistically more common. $\chi^{2}=14.1 . P<0.001$ 


\section{Hyponatremia}

A minimum of five serum sodium determinations was available in 184 patients, $80 \%$ of the total. Hyponatremia was noted in 37 patients, $20 \%$ of the evaluated patients. As shown in Table 7, a disproportionate number of patients with hyponatremia was found among those with $\mathrm{PH}$. One patient in the $\mathrm{PH}$ group had been treated wtih diuretics, and one in the control group had hyperlipidemia 'pseudohyponatremia'.

Table 3 Risk of postural hypotension by grade of paralysis in myelopathy patients with lesions above $\mathrm{T} 7$

\begin{tabular}{lccc}
\hline $\begin{array}{l}\text { Grade of Paralysis } \\
\text { (Above T7) }\end{array}$ & $\begin{array}{c}\text { Ephedrine } \\
\text { patients }\end{array}$ & $\begin{array}{c}\text { Non-Ephedrine } \\
\text { patients }\end{array}$ & Total \\
\hline Motor complete & $26(25)$ & 80 & 106 \\
Motor incomplete & $4(8)$ & 47 & 51 \\
\hline
\end{tabular}

Percentages are in parentheses. $\chi^{2}=10.9, P<0.001$

Table 4 Risk of postural hypotension by level and grade of paralysis in myelopathy patients with lesions above T7

\begin{tabular}{lccc}
\hline $\begin{array}{l}\text { Level and grade } \\
\text { of paralysis }\end{array}$ & $\begin{array}{c}\text { Ephedrine } \\
\text { patients }\end{array}$ & $\begin{array}{c}\text { Non-Ephedrine } \\
\text { patients }\end{array}$ & Total \\
\hline $\begin{array}{l}\text { Cervical motor } \\
\text { complete }\end{array}$ & $24(33)$ & 51 & 73 \\
$\begin{array}{c}\text { Cervical motor } \\
\text { incomplete }\end{array}$ & $3(7)$ & 45 & 48 \\
$\begin{array}{l}\text { Thoracic } 1-7 \\
\text { motor complete }\end{array}$ & $2(7)$ & 31 & 33 \\
$\begin{array}{c}\text { Thoracic } 1-7 \\
\text { Phori }\end{array}$ & $1(33)$ & 2 & 3 \\
\hline
\end{tabular}

Percentages of totals are in parentheses. Comparing the prevalence of ephedrine use in patients with cervical, motor complete lesions with that of all other levels and grades, $\chi^{2}=24, \mathrm{P}<0.001$

Table 5 Symptoms and signs of postural hypotension in myelopathy patients

\begin{tabular}{ll}
\hline Findings & Patients \\
\hline Dizziness or fainting & $30(100)$ \\
Fatigue or weakness & $20(67)$ \\
Visual disturbance & $17(57)$ \\
Dyspnea & $16(53)$ \\
Behavioral disturbance & $4(13)$ \\
Restlessness ('figity') & $4(13)$ \\
\hline
\end{tabular}

Percentages are in parentheses: restlessness was volunteered

Table 6 Factors precipitating postural hypotension

\begin{tabular}{lr}
\hline Factor & Patients \\
\hline Hot weather & $23(77)$ \\
Bowel care & $10(33)$ \\
Meals & $9(30)$ \\
Turning in bed & $4(13)$ \\
\hline
\end{tabular}

Percentages are in parentheses
Simultaneous measurement of serum sodium and urine osmolality in five patients revealed a persistence of ADH activity in the presence of hyponatremia, Table 8. Despite the ADH activity, presumably to preserve volume by retention of water, there was little evidence of salt retention, for the same purpose, except for Patient 5.

\section{Treatments}

Treatments reported by the patients have been summarized in Table 9. Most of the various forms of physical therapy were employed by the patient during the day, to temporarily correct PH. Thus patients with reclining wheelchairs could tip backwards at will while others bent forward to relieve symptoms.

Pharmacotherapy was also monitored by the patient. Thus ephedrine was sometimes taken only if initial dizziness could not be overcome after sitting up for $30 \mathrm{~min}$. Ephedrine was also repeated later in the day if necessary, although failures by the patient to recognize the need for repeat medication were observed.

Table 7 Prevalence of hyponatremia in patients with and without postural hypotension

\begin{tabular}{lccc}
\hline & $\begin{array}{c}\text { Ephedrine } \\
\text { patients }\end{array}$ & $\begin{array}{c}\text { Non-Ephedrine } \\
\text { patients }\end{array}$ & Total \\
\hline Hyponatremia & 15 & 25 & 40 \\
No Hyponatremia & 13 & 132 & 145 \\
\hline$\chi^{2}=20.8, P<0.001$ & & &
\end{tabular}

Table 8 Renal handling of salt and water in the presence of hyponatremia

\begin{tabular}{lccc}
\hline Patient & $\begin{array}{c}\text { Serum sodium } \\
(\mathrm{mEq} / \mathrm{L})\end{array}$ & $\begin{array}{c}\text { Urine } \\
\text { osmolality } \\
(\mathrm{mOsm} / \mathrm{Kg})\end{array}$ & $\begin{array}{c}\text { Urine sodium } \\
(\mathrm{mmol} / \mathrm{L})\end{array}$ \\
\hline 1 & 123 & 192 & 21 \\
2 & 126 & 243 & 89 \\
3 & 126 & 334 & 80 \\
4 & 130 & 289 & 108 \\
5 & 131 & 152 & 10 \\
\hline
\end{tabular}

Table 9 Numbers of patients receiving various treatments of postural hypotension among the 30 patients surveyed

\begin{tabular}{lr}
\hline Physical therapy & 16 \\
Reclining & 5 \\
Bending forward & 4 \\
Binders & 4 \\
Return to bed & \\
Chemical therapy & 30 \\
Ephedrine & 6 \\
Salt & 3 \\
Fludrocortisone &
\end{tabular}


Table 10 Salt loading in a hypotensive, hyponatremic patient

\begin{tabular}{lccccc}
\hline Date & $\begin{array}{c}\text { Serum sodium } \\
(\mathrm{mEq} / \mathrm{L})\end{array}$ & $\begin{array}{c}\text { Urine osmolality } \\
(\mathrm{mOsm} / \mathrm{Kg})\end{array}$ & $\begin{array}{c}\text { Urine sodium } \\
(\mathrm{mmol} / \mathrm{L})\end{array}$ & $\begin{array}{c}\text { Urine salt } \\
(\mathrm{g} / \mathrm{day})\end{array}$ & $\begin{array}{c}\text { Creatinine clearance } \\
(\mathrm{cc} / \mathrm{min})\end{array}$ \\
\hline 14 Nov 95 & 123 & 306 & 56 & 9.0 & 56 \\
14 Dec 95 & 124 & & 54 & 12.7 & 53 \\
29 Jan 96 & 129 & 320 & 88 & 20.3 & 70 \\
8 Jul 96 & 130 & 98 & 23.3 & 68 \\
\hline
\end{tabular}

The source of salt intake consisted of bouillon cubes ( $2 \mathrm{~g}$ sodium chloride per cube) and table salt

Salt supplementation with meals was suggested to four patients who then monitored their intake to balance relief of symptoms with bothersome ankle swelling. Three of these patients were successful to the point of becoming independent of the use of ephedrine. The fourth patient, who also improved symptomatically, demonstrated improved renal blood flow during the period of salt loading, Table 10. The hyponatremia in this patient was partially corrected.

\section{Discussion}

The greater prevalence of $\mathrm{PH}$ in patients with higher levels of paralysis is consistent with the previously reported inverse relationship of blood pressure to level of paralysis. ${ }^{11}$ The highest risk group for $\mathrm{PH}$ consisted, not surprisingly, of those with the greatest neurological deficit, tetraplegia and a motor complete grade of paralysis. The typical traumatic myelopathy consisting of central necrosis, the more extensive neurological deficit suggests a greater chance of cord damage extending to the intermediolateral columns, the sympathetic tracts. ${ }^{12}$

The symptoms themselves are generally understandable as manifestations of reduced cerebral flow. It is interesting to note that Gonzales et al. ${ }^{6}$ found that reductions in blood pressure, induced by orthostasis in tetraplegic subjects, did not correlate with symptoms of $\mathrm{PH}$, whereas the extent of cerebral blood flow slowing, as measured by the transcranial doppler technique, did. The intactness of the autoregulation of cerebral blood flow appears to be important in the symptomatology of $\mathrm{PH}$ in myelopathy patients.

As recognized for other neurological and medical conditions associated with $\mathrm{PH}$, feeling faint or dizzy (used interchangeably by patients), visual disturbances ('white outs', 'black outs'), and weakness and fatigue are common and explainable by cerebral hypoperfusion. ${ }^{4,5}$ Dyspnea, associated with PH in this survey, but not generally recognized as a symptom of $\mathrm{PH}$, may also represent cerebral hypoperfusion.

The exacerbating factors of hot weather, or meals representing a steal of circulation by the cutaneous or splanchnic systems - are typical in patients with postural hypotension. ${ }^{4,5}$ However, bowel care, characterized by long periods of sitting and multiple purgative treatments, may be unique to myelopathy patients as a precipitation factor in PH. Furthermore, position change, even with the patient lying in bed, can provoke symptoms. For this reason the term postural hypotension is preferable to orthostatic hypotension.

The early onset of $\mathrm{PH}$ in most patients was expected, but the late onset was not. In the same sense, the patient reports of symptoms worsening with time was not anticipated. Conceivable explanations are neuronal dropout in the damaged intermediolateral columns as in the Shy Drager syndrome, ${ }^{13}$ post traumatic syringomyelia, ${ }^{14}$ destabilization of blood pressure associated with bowel or bladder distention, and overtreatment with drugs which can produce hypotension - eg antispastics, inhibitors of angiotensin I converting enzyme, calcium channel blockers and diuretics. ${ }^{4,95}$

The failure of the sympathetic nervous system to protect the circulation against gravity in these patients is evidenced by reduced levels of catecholamines and loss of vasomotor adjustments. ${ }^{1,7,16,17} \mathrm{~A}$ further response to $\mathrm{PH}$ is the activation of the reninangiotensin-aldosterone system (RAS), in an attempt to preserve renal blood flow by sodium retention, extracellular volume expansion, and possibly increasing mean arterial pressure. ${ }^{18-20}$ To the extent that afferents from the sympathetic nervous system are involved in RAS activation, disruption of the sympathetic nervous system may result in inadequate responsiveness by the RAS to the reduction in renal blood and an incomplete compensation for PH. ${ }^{21,22}$

An additional response to $\mathrm{PH}$ is that of $\mathrm{ADH}$, mediated via central vascular baroreceptors and vagal and glosso-pharyngeal nerves, bypassing any disruption of the spinal cord. The $\mathrm{ADH}$ response to orthostasis is greater in tetraplegic patients than in neurologically intact subjects. ${ }^{82}$ Retention of a water load is greater in tetraplegic patients, again indicating unusual ADH activity. ${ }^{24}$ To the extent that RAS fails to compensate for $\mathrm{PH}$, the $\mathrm{ADH}$ response will predominate and hyponatremia will develop.

Treatments of $\mathrm{PH}$, whether physical or chemical, were generally effective and complementary. Graduated sitting often 'toned up' the circulation sufficiently to prevent symptoms during the day. Reclining or bending foward was also effective but short lived. Although a single dose of ephedrine in the morning was usually sufficient, it was observed that some patients failed to recognize the need for a repeated dose of this medication late in the day. Salt loading, 
usually patient monitored by addition of table salt or bouillon to the diet, was effective in the reduction of symptoms, sometimes at the expense of unwanted pedal edema. An improvement in renal blood flow with salt loading in instances of borderline renal failure associated with hypovolemia can be demonstrated. ${ }^{25}$ A similar enhancement of cerebral circulation with salt loading in the $\mathrm{PH}$ patients is implied.

It is concluded that postural hypotension is a relatively common problem for patients with myelopathy at levels above the mid thoracic, that the clinical course - one of intermittent cerebral insufficiency can be exacerbated by various physical and pharmacological challenges, and that salt and water metabolism is frequently abnormal.

\section{References}

1 Guttmann L, Munroe AF, Robinson R, Walsh JJ. Effect of tilting on the cardiovascular responses and plasma catecholamine levels in spinal man. Paraplegia 1963; 1: 4-18.

2 Takeda K, Kanno K, Minami T, Katsurada K. Hemodynamic and respiratory function following acute spinal cord injury. No To Shinkei 1977; 19: 639-645.

3 Corbett JL, Frankel HL, Harris PJ. Cardiovascular responses to tilting in tetraplegic man. J Physiol 1971; 215: 411-431.

4 Mathias CJ. Orthostatic hypotension, mechanisms and influencing factors. Neurology 1995; 45 (Suppl 5): S6-11.

5 Polinsky RJ, Martin JB. Chapter 379: Disorders of the autonomic nervous system. In: Isslebacher KJ et al. (eds). Harrison's Principles of Internal Medicine. 13th edn. McGrawHill: New York, 1994, pp 2344-2347.

6 Gonzalez $\mathrm{F}$ et al. Autoregulation of cerebral blood flow in patients with orthostatic hypotension after spinal cord injury. Paraplegia 1991; 29: $1-7$.

7 Mathias CJ et al. Plasma catecholamines, plasma renin activity and plasma aldosterone in tetraplegic man, horizontal and tilted. Clin Sci Mol Med 1975; 49: 291 - 299.

8 Sved AF, McDowell FH, Blessing WW. Release of antidiuretic hormone in quadriplegic subjects in response to head-up tilt. Neurology 1985; 35: 78-82.
9 Soni BM, Vaidyanthan S, Watt JWH, Krishman KR. A retrospective study of hyponatremia in tetraplegic paraplegic patients with a review of the literature. Paraplegia 1994; 32: 597 607.

10 Sica DA et al. Prostaglandin in E2 excretion in spinal cord injury patients. J Am Paraplegia Soc 1984; 7: 27-30.

11 Frankel HL, Michaelis LS, Golding DR, Beral V. The blood pressure in paraplegia. Paraplegia 1972; 10: $193-200$.

12 Wozniewicz B, Filipowiz K, Swiderska SK, Deraka K. Pathophysiological mechanism of traumatic cavitation of the spinal cord. Paraplegia 1983; 21: $312-317$.

13 Kakulas BA, Tan N, Oieda VJ. The neuropathology of progressive autonomic failure of central origin (the Shy-Drager syndrome). Clinical Experimental Neurol 1986; 22: 103-111.

14 Rossier AB, Foo D, Shilleto W, Dyro F. Posttraumatic cervical syringomyelia. Brain 1985; 108: 439-461.

15 Field MJ, Lawrence JR. Complications of thiazide diuretic therapy: an update. Med J Australia 1986; 144: 641-644.

16 Silver JR. Circulatory reflexes in spinal man. Paraplegia 1965; 2: $235-246$

17 Bidart Y, Maury M. The circulatory behaviour in complete chronic paraplegia. Paraplegia 1973; 11: $1-24$.

18 Cardus D, McTaggart WG. Body sodium and potassium in men with spinal cord injury. Archiv Physical Med Rehabil 1985; 66: $154-159$.

19 Kooner JS et al. Recumbency induces hypertension, diuresis and naturesis in autonomic failure, but diuresis alone in tetraplegia. $J$ Hypertension 1987; 5 (Suppl 5): S327-329.

20 Mathias CT et al. Renin release during head-up tilt occurs independently of sympathetic neuron activity in tetraplegic man. Clin Sci 1980; 59: 251-256.

21 Ohtomo Y, Meister B, Hokfelt T, Aperia A. Coexisting NPY and $\mathrm{NE}$ synergistically regulate renal tubular NA +, K(+)-ATPase activity. Kidney International 1994; 45: $1606-1613$.

22 Beck FW, Sowers JR, Sicca D, Welch BG. Absent aldosterone response to metoclopramide in patients with high spinal cord transection: evidence that metoclopramide stimulates aldosterone secretion through central pathways. Life Sciences 1985; 36: $2435-2444$.

23 Williams HH et al. Nonosmotic stimuli alter osmoregulation in patients with spinal cord injury. J Clin Endocrin Metab 1990; 71: $1536-1543$.

24 Silver JR, Doggart JR, Burr RG. The reduced urinary output after spinal cord injury: a review. Paraplegia 1995; 33: $721-725$.

25 Peer G, Wigler I, Aviram A. Prolonged volume depletion imitating end-stage renal failure. Am J Med Sciences 1987; 194: $214-217$. 